OPEN ACCESS

Edited by:

Susana Araújo,

University of Lisbon, Portugal

Reviewed by: Isabel Silva Leite,

University of Evora, Portugal

Cameron Downing,

Leeds Trinity University, United Kingdom

*Correspondence: Jean-Paul Fischer jean-paul.fischer@univ-lorraine.fr

Specialty section:

This article was submitted to

Language Sciences,

a section of the journal

Frontiers in Communication

Received: 02 June 2021 Accepted: 20 September 2021

Published: 05 October 2021

Citation:

Fischer J-P and Luxembourger $C$ (2021) A Test of Three Models of

Character Reversal in Typically

Developing Children's Writing.

Front. Commun. 6:719652.

doi: 10.3389/fcomm.2021.719652

\section{A Test of Three Models of Character Reversal in Typically Developing Children's Writing}

\author{
Jean-Paul Fischer ${ }^{1 *}$ and Christophe Luxembourger ${ }^{2}$ \\ ${ }^{1}$ Laboratory 2LPN, Université de Lorraine, Nancy, France, ${ }^{2}$ Laboratory 2LPN, Department Psychology, Université de Lorraine, \\ Nancy, France
}

Multisensory learning to read involves, to a large extent, learning to write. A major problem in the initial teaching of handwriting is preventing children from producing reversed letters, especially when the reversed letters are identical to other letters. Torres et al. (2021) offer an efficient method for remediating this problem. Here, we analyze the reversals in their writing data, obtained on Brazilian first-graders ( $M_{\text {age }}=6.0$ years). Surprisingly, this analysis led to the observation that the first graders almost systematically reverse both the letters $b$ and $d$ in the particular copying conditions (the students look at one letter at a time for $3 \mathrm{~s}$, then immediately after they had to write it while blindfolded). We first describe succinctly and discuss three models susceptible to account for reversal writing, with the aim to question their capacity of account for the curious observation just mentioned. The three models respectively attribute a major role to 1) initial (perceptive) mirror equivalence, 2) intra-hemispheric transfer, 3) orientation of the letters. Because none of the three models examined accounts convincingly for the observation, we accommodated and specified Model 2, adding also a major idea of Model 3. The resulting model assumes that the mirror-letter reversed image representation ( $b$ for $d$ and vice-versa) is strongly activated in the right cerebral hemisphere, and that the top-down processes originating from this hemisphere were exacerbated by the eyes closed condition. Of course, this post-hoc and speculative model should be tested in other conditions and with other children.

Keywords: mirror writing, letter reversal, interhemispheric transfer, mirror letter, first grade

\section{INTRODUCTION}

Knowledge is often acquired through reading and transmitted through writing. Not surprisingly, much research then supports a unidirectional relationship from reading to writing (Ahmed et al., 2014; Kim et al., 2018). For example, Ahmed et al.'s modeling suggested that a unidirectional reading-to-writing model was better at the word and text levels of analysis. However, their modeling also revealed that a bidirectional model best fit the sentence-level data. Besides, the study of the relation between reading and writing necessarily excludes children who cannot sufficiently read. For example, the Kim et al.'s longitudinal data do not include students before third grade (in the United States). For learners who are beginning to read-typically preschoolers or first graders at the beginning of the school year-, and at the letter-level, the relationship between reading (or letter recognition) and writing might be somewhat different.

First, children in literate societies learn about some of the formal properties of writing long before they go to school (Treiman and Kessler, 2014). In modern societies, they develop some knowledge 
about the outer form of writing as early as 2 or 3 years of age (Treiman, 2017). Second, reading and writing are usually taught/ learned at the same time. Perhaps this is why they have been found to be associated in the brain, at least at the letter-level (Longcamp et al., 2016). Third, teaching/learning, whether at school or at home, often begins with a copy/writing task (especially of the first name) that combines or even merges the two tasks. Fourth, reading is fundamentally addressed in the visual modality. Braille reading seems to be an exception, but it only concerns a limited population: blindness is rare, and not all blind people read Braille; furthermore, Braille reading declines with the today multiplication of audio-books and voice synthesis software that read aloud any document in digital version. In consequence, multisensory learning of reading should mainly be indirect, namely through multisensory learning to write. The research by Torres et al. (2021) seems an example of how multisensory learning to read can be improved by learning to write, even if multi-sensory learning is not a panacea (Madan and Singhal, 2021). Indeed, in their brief targeted intervention (30 min/day for 3 weeks), Torres et al. (2021) used a majority of learning to write activities, namely "air-writing" and "writing on a paper," in addition to a tactile perception of letter traces activity, "perceiving letters on hands." Finally, the contribution of learning to write to learning to read was empirically demonstrated in French preschoolers (Ouzoulias et al., 2000).

One of the main difficulties in reading beginners is the distinction of a letter from its reversal, which is fundamental for distinguish $\mathrm{b}$ and $\mathrm{d}$, or $\mathrm{p}$ and $\mathrm{q}$. Thus, it is important to know that writing and reading, at least its letter recognition subcomponent, do not raise the same treatment of reversal in children (Fischer and Luxembourger, 2020; but see McIntosh et al., 2018b). Many researchers certainly consider the two tasks to be closely related, but given their relative importance, they investigate reading exclusively, following the example of Wechsler and Pignatelli (1937). By the way, research on adults or older children is forced to limit itself to reversal in reading, since such participants no longer make letter reversal in writing. Moreover, in reading, letter reversal can hardly be studied directly. Indirectly, it is often investigated with priming techniques, on typical adults (Duñabeitia et al., 2011; Borst et al., 2015; Ahr et al., 2017; Soares et al., 2019; Soares et al., 2021) or typically developing children beyond age six (Perea et al., 2011; Ahr et al., 2016; Brault-Foisy et al., 2017).

Yet, a particular reading dysfunction-dyslexia, or strephosymbolia, as it was first named by Orton (1925) - has been specifically studied in its relationship to reversal (Fernandes and Leite, 2017). Historically, Orton and Gillingham (1933) noted that the twist in reproduction, suggested by mirror writing, is "of considerable interest and probably of some prognostic value" (p. 268). As a support, they noted that most of the children they have seen who exhibited this initial tendency to twist also experienced considerable difficulty in reading later on. More recently, Lachmann (2008) noted that reversal errors have been diagnosed as one of the primary symptoms of developmental dyslexia. However, Cheng-Lai et al. (2013) report no reversal errors in their sample of 45 nine-years-old Chinese children with dyslexia, despite the inclusion of a 70-item left/right reversal subtest assessing ability to identify the correct orientation of orthographic units, such as simple Chinese characters and Arabic numbers. Indeed, the argument used by Orton and Gillingham sounds like a tautology since almost all children-and thus also future dyslexic children-exhibit this initial tendency to twist. For example, in Fischer and Tazouti (2012) Experiment 2, approximately 95\% of the 356 typical children reversed at least one character (uppercase letter or digit) out of the 33 characters they were asked to write under dictation. Furthermore, Orton and Gillingham's argument does not imply a causal relationship. In order to refine then our understanding of the relationship between mirror writing and dyslexia, the selection of a relevant model of handwriting reversal by typical children is a first step. This first step, at least for letter reversal, was the main objective of the present paper.

Accordingly, we will successively describe three candidate models for explaining the initial mirror reversal in writing by typically developing children. An empirical test of these models was possible with the recent data made publically available by Torres et al. (2021). In addition, these data also allowed us to investigate the relationship between mirror writing and mirror image discrimination in a visual task. The result of the test led to a speculative accommodated model for the particular condition of copying/writing blindfolded used by Torres et al. (2021).

\subsection{Model 1 of Initial Mirror-Equivalence and Mirror-Letter Confusion}

Model 1 is premised on brain blindness to letter orientation in children. In this model letter perception begins developmentally with visual processes that are orientation insensitive (Blackburne et al., 2014; Pegado et al., 2014; Torres et al., 2021). As Torres et al. point out, this creates then "confusion between mirror letters (e.g., b-d in the Latin alphabet)" (p. 1).

Here we will review studies showing that the basis of this model, that is initial brain blindness to character orientation in very young children, is inconsistent with the data, and that "memory-image generalization describes an effect of memory formation and not of perception" (Lachmann and Geyer, 2003). First, there are many old behavioral tests supporting this conclusion. Over and Over (1967) showed that 3-6 years-old children can discriminate between mirror-image oblique lines under detection conditions but not under recognition conditions. Over (1967) concludes that "the child perceives that mirror image obliques differ in orientation but seems unable to remember from trial to trial which is the "correct" oblique" (p. 1272). In the 1970s, some of Bryant (1969) and Bryant (1973) results were interpreted in a controversial way. Bryant has shown that two non mirrorimage obliques are just as confused as two mirror-image obliques by 4-7 year-olds. However, we refer here simply to Bryant (1969) observation that 5 year-olds made very few errors in a simultaneous presentation but performed at chance level in a successive comparison of obliques. In accordance, Corballis and Zalik (1977) concluded that, what is clear about Bryant's findings, "is that the difficulty of discriminating mirror-image obliques is a problem of memory rather than of perception" ( $p$. 516). Even babies (3-4 month-old) were able to discriminate differences in 
orientation, although they tended to view mirror images as equivalent stimuli (Bornstein et al., 1978).

Second, there are physiological evidence that orientation is detected very early in the primary visual cortex (also known as V1). Hubel et al. (1977) demonstrated the presence of a system of orientation columns in the macaque monkey visual cortex. Whereas afferent thalamic neurons are generally orientation insensitive (Priebe, 2016), a key emergent property of V1 is the orientation selectivity of its neurons (Dragoi et al., 2000; but see Antinucci and Hindges, 2018). Dragoi et al. showed that the development of orientation tuning does not require visual experience, although selective experience in early life can modify the orientation preference of neurons. Garg et al. (2019) found that a notable proportions of V1 neurons strongly preferred color stimuli and were also orientation selective. Thus, processing of orientation and color seems combined at the earliest stages of visual processing. Finally, Jia et al. (2021) trained adult participants in an orientation discrimination task while using functional magnetic resonance imaging (fMRI), thereby revealing orientation-specific neural patterns in $\mathrm{V} 1$ before training.

Third, mirror confusion could then occur because the perceived orientation information is lost in the memory code. Because this forgetting leads to non-discrimination of an image from its mirror, it appears as a generalization process, forgetting being a central mechanism of generalization (Vlach and Kalish, 2014). The credibility of this temporary forgetting is strengthened by sensitivity to mirror reversals in an earlier visual processing object-selective region, the lateral occipital sulcus, followed by tolerance to mirror reversals in one object-selective region, the posterior fusiform sulcus (Dilks et al., 2011). Rollenhagen and Olson (2000) discovered cells with mirror-symmetric tuning, and Freiwald and Tsao (2010) found, in the macaque face-processing system, that such cells were agglomerated within a single intermediate node, not in the most posterior face-selective region as one might have expected in case of non-distinction, initially in V1, between an image and its mirror. In humans, literate individuals diverge from illiterate in the ability to discriminate horizontal mirror images (enantiomorphy) at a later, postperceptual representational level. Therefore, the deficiency in enantiomorphy seems not a problem in input coding (Kolinsky et al., 2011).

Fourth, Fischer and coworkers compared the easiness, with respect to reversal errors, of a character copying task with a character writing from memory task. Indirect confirmation of this easiness was provided by two experiments by Fischer and Tazouti (2012). In their Experiment 1a, on 5-6 year-old children, 143 of them copied the eight asymmetrical digits and wrote eight asymmetrical capital letters from memory, and 156 others copied these letters and wrote the digits from memory. The result was very clear: The children reversed the characters much less frequently (and even very rarely) when they copied them $(0.4 \%$ reversal) than when they wrote them from memory $(20.4 \%$ reversal). In their Experiment 1b, 205 children (4-5 years-old) produced only $7.3 \%$ reversals in copying the digits, whereas 153 children (5-6 years-old, from Expt 1a) produced $21.8 \%$ reversals in writing the digits from memory. A more direct confirmation comes from the longitudinal study by

\begin{tabular}{|c|c|c|c|c|}
\hline Child & \multirow{2}{*}{\multicolumn{2}{|c|}{$\begin{array}{c}\text { Copy from a model } \\
\text { at age } 4\end{array}$}} & \multicolumn{2}{|c|}{ Writing from memory } \\
\hline Age in years & & & at age 5 & at age 6 \\
\hline $\begin{array}{l}\text { Boy, } \\
\text { right hand }\end{array}$ & 3 & 3 & $C$ & 3 \\
\hline at age & \multicolumn{2}{|c|}{4.61} & 5.71 & 6.72 \\
\hline $\begin{array}{l}\text { Girl, } \\
\text { right hand }\end{array}$ & 1 & & 6 & $J$ \\
\hline at age & \multicolumn{2}{|c|}{4.23} & 5.24 & 6.27 \\
\hline $\begin{array}{l}\text { Girl, } \\
\text { right hand }\end{array}$ & 7 & 7 & $f$ & 7 \\
\hline at age & \multicolumn{2}{|c|}{4.58} & 5.57 & 6.60 \\
\hline $\begin{array}{l}\text { Boy, } \\
\text { right hand }\end{array}$ & Z & 2 & 5 & 2 \\
\hline at age & \multicolumn{2}{|c|}{4.27} & 5.26 & 6.16 \\
\hline
\end{tabular}

FIGURE 1 | Characters correctly copied at age four, mirror written at age five, and correctly written at age six by the same children (data from Fischer and Koch, 2016).

Fischer and Koch (2016) who found that the 166 children in the middle section of the French école maternelle produced only $3.6 \%$ reversals in copying the characters, whereas the same children, when they had integrated the upper section, produced $25.4 \%$ mirror reversals in writing the characters from memory. As shown in Figure 1, many children copied correctly a character when aged 4 years, mirror wrote the same character at age 5 years, and wrote it correctly at 6 years.

\subsection{Model 2 of Interhemispheric Reversal}

Model 2 relies on different character representations in the two hemispheres due to interhemispheric mirror-image reversal during the transfer (Corballis and Beale, 1976). More specifically, Corballis et al. (2010) suggested that reversed exemplars of the letters may be laid down in the right cerebral hemisphere.

First, reinforcing our preceding conclusion, Corballis (2018) underlines that the mirror-image confusion "is almost certainly a matter of recognition rather than perception per se" (p. 3), and, further, that "early processing retains left-right information for perception, but this is lost at the later stage where recognition takes place" (p. 4). In Corballis' theory, the mirror-image storage is achieved through the process of interhemispheric mirror-image reversal as a result of homotopic connections between the hemispheres. By this process, each hemisphere perceives correctly, for example, the symbol $b$, but in the memory storage process, the representation of $\mathrm{b}$ is transferred and reversed between hemispheres.

Evidence for the implication of the anterior commissure in the transfer was obtained in great part on patients without functional corpus callosum. Notably, a callotomized patient, DDV, showed systematic left-right reversal of the letters in the left visual field (i.e., right hemisphere), with a bias to respond $b$ in a b-d discrimination task in the left, but not right visual field (Corballis et al., 2010). Interestingly, the same research demonstrates that even in normal participants, discrimination 
TABLE 1 | Reversal of the asymmetrical letters, in percentages, after Richmond (2012) for lowercase letters and Fischer and Luxembourger (2018a, Table 2) for capital letters.

\begin{tabular}{|c|c|c|}
\hline Letter & $\begin{array}{l}\text { Lowercase } N=126 ; \text { Grade: } \\
1-4\end{array}$ & $\begin{array}{c}\text { Uppercase }^{\mathrm{a}} N=679 ; \\
\text { Age: } 5.72 \text { years }\end{array}$ \\
\hline$A$ & 0 & - \\
\hline$B$ & 0.8 & 6.49 \\
\hline C & 0.8 & 10.95 \\
\hline$D$ & 1.6 & 6.09 \\
\hline$E$ & 0 & 7.84 \\
\hline $\mathrm{F}$ & 0 & 8.09 \\
\hline $\mathrm{G}$ & 0 & 6.29 \\
\hline $\mathrm{H}$ & 0 & - \\
\hline 1 & 0.8 & - \\
\hline J & 9.5 & 47.86 \\
\hline K & 0 & 4.62 \\
\hline $\mathrm{L}$ & 1.6 & 11.14 \\
\hline$M$ & 0 & - \\
\hline $\mathrm{N}$ & 0 & 2.46 \\
\hline 0 & 0 & - \\
\hline$P$ & 1.6 & 7.70 \\
\hline$Q$ & 0.8 & 13.08 \\
\hline $\mathrm{R}$ & 0 & 6.42 \\
\hline$S$ & 2.4 & 19.02 \\
\hline $\mathrm{T}$ & 0.8 & - \\
\hline$U$ & 0 & - \\
\hline V & 0 & - \\
\hline W & 0 & - \\
\hline$X$ & 0 & - \\
\hline$Y$ & 0 & - \\
\hline Z & 11.9 & 51.32 \\
\hline
\end{tabular}

${ }^{a}$ Dash are for symmetrical capital letters.

of mirror-image letters depends on matching to an exemplar, for which the right-hemisphere is dominant.

Experimentations on non-human animals also support the implication of the hippocampal commissure in the transfer. It would be interesting to further investigate this implication as it may help to understand children's learning of character orientation. Indeed, as Fischer (1999) points out for the digit 3, learning to bind the oral name of a digit and its Arabic handwriting is fundamentally a declarative learning. And this type of learning is precisely a specificity of the hippocampus (Squire, 1992; Eichenbaum, 2004; Menon and Chang, 2021). Thus, the inhibition of interhemispheric transfer by way of the hippocampal commissure could support the behavioral observations of mirror-image inhibition, reported or suggested by many authors (Duñabeitia et al., 2011; Borst et al., 2015; Ahr et al., 2016; Brault-Foisy et al., 2017; Soares et al., 2019). This suggestion fits well with the description of the hippocampus as a "suppressor of inappropriate associations" (McNaughton and Wickens, 2003), less well albeit not in contradiction with its capacity to abstract and generalize ${ }^{1}$ from a format to the other (Viganò et al., 2021).

${ }^{1}$ The generalization referred to here is not mirror symmetrization, but, for example, the generalization from one correct graphic form to another (also correct), which is particularly important for solving the problem of spatial variability of handwritten letters.
In addition, Mather (2001) suggestion that dyslexia develops from learning the alphabet in the wrong hemisphere fits well with Corballis' theory. A literature review leads Mather to write that "dyslexics perform as if there were little interaction of their two cerebral hemispheres" (p. 287), and Mather et al. (2015) to the suggestion that "spontaneous mirror-writing may reflect right hemisphere representations laid down during the beginning stages of handwriting learning" (pp. 570-571). Moreover, Gordon (1980) hypothesized that dyslexics were "locked" into a right hemisphere mode of processing which governed all their cognitive activity. Therefore, Mather's suggestion-dyslexic children use the wrong hemisphere (usually the right depository of the reversed representations) - can seem compelling. However, because the suggestion implies a causal relationship between reversal and dyslexia, it seems at odds with our discussion of Orton and Gillingham's argument in the introduction, as well as many other arguments against causality. For example, that by Treiman et al. (2014) that reversal errors do not predict later reading ability, whereas other production errors do.

However, Model 2 does not explain why, in writing, the intrusion of reversal representations affects some letters (see the present Tables 1, 2) and digits (Fischer and Luxembourger, 2018a, Table 1) much more than others. With Mather's wording, the question becomes: Why do children use the wrong hemisphere for some letters and not for others?

\subsection{Model 3 of Character Right Orienting}

Model 3 of letter orientation in the direction of writing (Fischer, 2017) starts with the observation that children have few problems copying the characters, but the process of memorization erases the character orientations (cf., Dehaene, 2009). Because of the resulting un-oriented representation of the characters, the children must choose an orientation when writing characters from memory. Then, the model adds a somewhat original idea (but see Simner, 1984; Simner, 2003; Treiman and Kessler, 2011): the characters themselves, rather than certain characteristics of the children (e.g., left-handedness), explain the reversal. This idea that characters, or more generally items, play a fundamental role in the participants' performance has long been overlooked in many areas of research, despite Clark (1973) seminal article in psycholinguistics. Generally, only participants' variability is taken into account in the widely practiced ANOVA and t-tests analysis of variance procedures (Judd et al., 2017). This is no longer the case since appropriate designs and analytic models that incorporate items' variation, known as mixed effects models, have been developed. Commenting on these new models, Brysbaert and Stevens (2018) strikingly note that "a revolution is taking place in the statistical analysis of psychological studies" (p. 1).

Fischer and colleagues then hypothesized that left-oriented characters - the digits 1, 2, 3, 7, and 9, and the capital letters J and $\mathrm{Z}$-should be more reversed than the other asymmetrical characters because children typically adopt the rule of orienting characters in the direction of writing, which in our culture is to the right. Left-orientation cannot be defined mathematically because the dynamics of writing must be taken into account to categorize certain characters (e.g., 4), but the evaluation of orientation by adult students has confirmed this 
TABLE 2 | Categorization of the letter-writings in the Baseline test.

\begin{tabular}{|c|c|c|c|c|c|c|c|c|}
\hline Letter & $\begin{array}{l}\text { Correct } \\
\text { writing }\end{array}$ & $\begin{array}{l}\text { Mirror } \\
\text { writing }\end{array}$ & $\begin{array}{c}\text { Vertical } \\
\text { mirror }\end{array}$ & $\begin{array}{l}\text { Double } \\
\text { mirror }\end{array}$ & $\begin{array}{c}\text { Other } \\
\text { product. }\end{array}$ & $\begin{array}{l}\text { Non- } \\
\text { response }\end{array}$ & $\begin{array}{l}\text { Number } \\
\text { children }\end{array}$ & $\begin{array}{l}\text { Percent } \\
\text { mirror }^{a}\end{array}$ \\
\hline$B$ & 16 & 94 & 2 & 1 & 3 & 1 & 117 & $85 \%$ \\
\hline C & 101 & 1 & 0 & 0 & 5 & 10 & 117 & $1 \%$ \\
\hline$A$ & 86 & 2 & 1 & 1 & 13 & 14 & 117 & $2 \%$ \\
\hline $\mathrm{F}$ & 83 & 3 & 0 & 0 & 6 & 25 & 117 & $3 \%$ \\
\hline$E$ & 85 & 11 & 1 & 1 & 9 & 10 & 117 & $11 \%$ \\
\hline $\mathrm{D}$ & 15 & 99 & 1 & 1 & 1 & 0 & 117 & $87 \%$ \\
\hline$G$ & 58 & 7 & 7 & 1 & 13 & 31 & 117 & $11 \%$ \\
\hline $\mathrm{H}$ & 76 & 24 & 0 & 0 & 12 & 5 & 117 & $24 \%$ \\
\hline$K$ & 73 & 14 & 0 & 0 & 7 & 23 & 117 & $16 \%$ \\
\hline$S$ & 33 & 78 & 0 & 0 & 1 & 5 & 117 & $70 \%$ \\
\hline Z & 13 & 100 & 0 & 0 & 4 & 0 & 117 & $88 \%$ \\
\hline$p$ & 30 & 73 & 1 & 5 & 4 & 4 & 117 & $71 \%$ \\
\hline j & 24 & 4 & 0 & 0 & 3 & 5 & 36 & $14 \%$ \\
\hline$q$ & 13 & 22 & 0 & 0 & 1 & 0 & 36 & $63 \%$ \\
\hline$r$ & 22 & 0 & 0 & 0 & 13 & 1 & 36 & $0 \%$ \\
\hline $\mathrm{t}$ & 18 & 3 & 1 & 0 & 11 & 3 & 36 & $14 \%$ \\
\hline$y$ & 24 & 2 & 0 & 0 & 8 & 2 & 36 & $8 \%$ \\
\hline
\end{tabular}

${ }^{a}$ Calculated taking into account only writings relevant to the discussion (i.e., horizontal mirror and correct writings).

categorization (Fischer, 2018). The hypothesis was subsequently widely supported, not only in the research by Fischer and colleagues (Fischer and Luxembourger, 2018a), but also by others (Treiman et al., 2014; McIntosh et al., 2018a; McIntosh et al., 2018b; Portex et al., 2018; see also Table 1).

Children who apply the right-orienting rule will reverse the leftoriented characters, whereas the children (rare in our culture) who apply a left-orienting rule would reverse the right-oriented characters. Therefore the within-children correlation between reversal of the left-oriented and right-oriented characters should be negative. This fine prediction was verified for the digits by Fischer (2013), and for the combined digits and capital letters by Fischer and Koch (2016). There are more left-oriented digits than right-oriented digits (five vs. three), and the right-orienting rule seems more usual than a left-orienting rule in our culture. Therefore, the within-child bi-serial correlation of reversal of any digit with the percentage of reversal in the subsample of other digits, should be greater for the left-oriented digits than for the right-oriented digits. If miswriting in 4-5 year-olds, as studied by Fischer and Thierry (2021), consists primarily in mirror writing, this other fine prediction was verified for the digits $1-5$ by these authors.

\section{AN EMPIRICAL TEST}

Torres et al. (2021) used a complex letter writing task as one of the measure allowing to assess the efficiency of first graders' learning to distinguish a letter and its mirror-image, $\mathrm{b}$ and $\mathrm{d}$ for example. Their data, which are publically accessible on https://osf.io/643jh/, or, more specifically, the children's writings on https://osf.io/ qc8bn/, offer the possibility to test our three models.

\subsection{Method}

\subsubsection{Participants}

The data on writing were collected by Torres et al. during three replicas including 32,60 , and 48 first-graders, respectively, with initial mean age 5.99 years (50.7\% girls). The children were recruited in Natal (Brazil), and tested in September for the Baseline, in October just after the Intervention, and about 120 days after in February of the following academic year (which starts in February in Brazil). Participants were randomly assigned to one of the two training groups, Training (T) or Training + Sleep $(\mathrm{T}+\mathrm{S})$, or one of the two control groups, Control (C) and Active Control (AC). They received a rudimentary phonics lesson on the letters before the baseline tests. Training consisted of multisensory-motor activities aimed to distinguish asymmetrical letters from their mirror version. In the Active Control (AC) group participants received similar multisensory-motor activities as in the training groups but played only with the symmetrical letters (e.g., A-X).

\subsubsection{Procedure}

In the writing task, participants had to copy the asymmetrical letters b, c, a, f, e, d, g, h, k, s, z, p, and, in Replica three, five additional letters ( $j, q, r, t, y)$. The letters were displayed in Arial 90 points (see Figure 2). Each child was given a blank sheet of paper divided into squares (one for each copy of the letter). The researcher showed one letter at a time for $3 \mathrm{~s}$, and immediately afterwards the participant had to write the letter blindfolded.

Torres et al. also included a visual discrimination task in which children had to decide if an image (a lowercase letter or an icon) is the same or different from another which was different, the same (though 25\% larger) or its mirror, respectively.

\subsubsection{Coding}

Children's productions were coded and classified into six categories (see Tables 2, 3, also Figure 2) by an experienced coder (one of the co-authors): 1) correct (readable); 2) horizontal mirror writing (left-right reversal); 3) vertical mirror writing (upside-down inversion); 4) double mirror writing (horizontal and vertical mirror); 5) other (other character, unreadable, intermediate writing); 6) No response (the corresponding case 


\begin{tabular}{|c|c|c|c|c|c|c|c|c|c|c|c|c|c|c|c|c|c|}
\hline Correct & a & b & C & $d$ & e & $f$ & $\mathrm{~g}$ & $\mathrm{~h}$ & j & k & $p$ & q & $r$ & $\mathrm{~s}$ & $\mathrm{t}$ & $y$ & $z$ \\
\hline Mir hor. & s & $d$ & 0 & $b$ & $\vartheta$ & 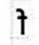 & $\mathrm{Q}$ & ก & l & X & q & $p$ & 1 & 2 & f & $V$ & $\Sigma$ \\
\hline Mir vert. & $\mathbf{s}$ & $p$ & $\mathrm{C}$ & $q$ & $\theta$ & t & a & $\mu$ & j & $K$ & b & d & L & 2 & f & $\lambda$ & $\Sigma$ \\
\hline Mir dbl. & e & $q$ & 0 & $p$ & $\partial$ & $t$ & 6 & 4 & I & 사 & d & b & $d$ & s & 7 & $\kappa$ & Z \\
\hline
\end{tabular}

FIGURE 2 | The asymmetrical lower case letters, originally displayed in Arial 90 dots, and their different mirrors: horizontal, vertical, double (both horizontal and vertical).

\begin{tabular}{|c|c|c|c|c|c|c|c|c|}
\hline Letter & $\begin{array}{l}\text { Correct } \\
\text { writing }\end{array}$ & $\begin{array}{l}\text { Mirror } \\
\text { writing }\end{array}$ & $\begin{array}{c}\text { Vertical } \\
\text { mirror }\end{array}$ & $\begin{array}{l}\text { Double } \\
\text { mirror }\end{array}$ & $\begin{array}{l}\text { Other } \\
\text { product }\end{array}$ & $\begin{array}{l}\text { Non- } \\
\text { response }\end{array}$ & $\begin{array}{l}\text { Number } \\
\text { writings }\end{array}$ & $\begin{array}{c}\text { Percent } \\
\text { mirror }^{\mathbf{a}}\end{array}$ \\
\hline b & 11 & 102 & 0 & 0 & 0 & 0 & 113 & $90 \%$ \\
\hline C & 96 & 2 & 0 & 0 & 1 & 14 & 113 & $2 \%$ \\
\hline a & 70 & 2 & 1 & 0 & 11 & 29 & 113 & $3 \%$ \\
\hline$f$ & 63 & 9 & 1 & 0 & 6 & 34 & 113 & $13 \%$ \\
\hline e & 79 & 2 & 2 & 2 & 9 & 19 & 113 & $2 \%$ \\
\hline d & 10 & 96 & 1 & 0 & 4 & 2 & 113 & $91 \%$ \\
\hline g & 59 & 8 & 7 & 1 & 5 & 33 & 113 & $12 \%$ \\
\hline h & 70 & 15 & 0 & 0 & 12 & 16 & 113 & $18 \%$ \\
\hline k & 51 & 11 & 0 & 0 & 16 & 35 & 113 & $18 \%$ \\
\hline s & 28 & 69 & 0 & 0 & 3 & 13 & 113 & $71 \%$ \\
\hline z & 11 & 94 & 0 & 0 & 1 & 7 & 113 & $90 \%$ \\
\hline$p$ & 23 & 82 & 1 & 1 & 2 & 4 & 113 & $78 \%$ \\
\hline j & 7 & 13 & 0 & 0 & 4 & 10 & 34 & $65 \%$ \\
\hline q & 10 & 20 & 1 & 0 & 3 & 0 & 34 & $67 \%$ \\
\hline$r$ & 20 & 1 & 0 & 0 & 8 & 5 & 34 & $5 \%$ \\
\hline $\mathrm{t}$ & 6 & 1 & 0 & 1 & 20 & 6 & 34 & $14 \%$ \\
\hline$y$ & 24 & 0 & 0 & 0 & 8 & 2 & 34 & $0 \%$ \\
\hline
\end{tabular}

${ }^{a}$ Calculated taking into account only writings relevant to the discussion (i.e., horizontal mirror and correct writings).

was blank). Quality of the writings was not taken into account, as long as a letters' left-right orientation was identifiable. Though they are sometimes difficult to read, this coding of the scanned children's writings generally poses no problem with respect to our primarily concern-reversal of b-d (and p-q).

\subsubsection{Hypotheses}

With respect to the reversal of the two crucial mirror-letters $b$ and $\mathrm{d}$ (the data for mirror-letter $\mathrm{q}$ are small), Model 1 predicts confusion or at least non-distinction between $b$ and $d$. If the children who already know the writing of the letters are excluded, this confusion could then lead children to reverse each letter-b in $\mathrm{d}$ and $\mathrm{d}$ in $\mathrm{b}$-in $50 \%$ of their writings. Consequently, by chance, only $25 \%$ of the children should both reverse b (in d) and $\mathrm{d}$ (in b). Model 2 does not predict systematic confusion, but $b$ should have the same chance being reversed in $d$ than $d$ in $b$. Model 3 predicts the reversal of $d$ in $b$, but not the reversal of $b$ in d. Only the third model allows prediction for the reversal of other individual letters. That is, the left-oriented letters ( $a, g, z, j, y)$ should be more reversed than the right-oriented letters $(c, f, e, h$, $\mathrm{k}, \mathrm{s}, \mathrm{r}, \mathrm{t}){ }^{2}$

${ }^{2}$ This categorization is consistent with Treiman et al. (2014) assessment on adult students, with the exception of $\mathrm{t}$, which is neutral in Treiman et al.
Concerning the relationship between the results of the visual discrimination and writing tasks, a logical hypothesis was that visual discrimination of mirrored images correlates with, and even explains for letter-icons, reversal in writing.

\subsection{Results}

For the Baseline, data of all children in the three replicas can be combined. Thus, we have writings from 117 children for all asymmetrical letters, except for the letters added in Replica 3 (see Table 2). The systematic analysis of the available writings of these 117 children, excluding data not relevant to this discussion (non-responses, other graphical productions, non-horizontal mirrors), led to $85 \%$ reversals of b (in d), $87 \%$ reversals of $d$ (in b). Furthermore, $75 \%$ of children reversed both b (in d) and d (in b).

With respect to the non-mirror letters (i.e., excluding b-d and $\mathrm{p}-\mathrm{q}$ ), the weighted mean, in Table 2 , of the left-oriented letters yields $36 \%$ reversal, and that of the right-oriented letters yields $21 \%$ reversal. If we look at the letters in a restricted sample of letters, without the mirror-letters and the insufficiently tested letters $j, q, r, t, y$, the weighted mean percentage reversal of the left-oriented letters yields $41 \%$ reversal, whereas that of the rightoriented letters yields 21\%. Calculating for each child a percentage of reversal for left- and right-oriented letters, the paired $t$-test confirms the higher reversal of the left-versus rightoriented letters, $t(116)=7.37, p<0.001$. 
For the post-intervention writings, we pooled the data from groups $\mathrm{C}$ and $\mathrm{AC}$ because there was no learning to distinguish an asymmetrical letter and its mirror in these two groups. In addition, we verified, separately for the immediate and long-term tests, that the percentage of mirror reversals did not differ significantly in the $\mathrm{C}$ and $\mathrm{AC}$ groups (both $p \mathrm{~s}>$ $0.20)$. We do not analyze the data in the groups $\mathrm{T}$ and $\mathrm{T}+\mathrm{S}$ because there were very few mirror reversals in these groups. We also pooled the data obtained in groups $\mathrm{C}$ and $\mathrm{AC}$ immediately after learning or 120 days after. Table 3 shows, in the second to last column, the number of opportunities to write a letter, with each student typically having two opportunities, one in the immediate test and one in the long-term test (but a few children were absent at one of the tests). A posteriori, the legitimacy of our pooling is supported by the very high positive correlation (Pearson's $r=0.99$ ) between the mirror writing percentages for the 12 systematically studied letters in the first observation (baseline) and the same percentages calculated with the pooled data.

The percentages of mirror reversal in Table 3 reinforce those of the baseline data in Table 2 , since $90 \%$ of the $\mathrm{b}$ are reversed in $d$ and $91 \%$ of the $d$ are reversed in $b$. In addition, we counted $79 \%$ pairs $(b, d)$ reversed in $(d, b)$ in the 113 examined pairs.

With respect to the non-mirror letters (i.e., excluding b-d and p-q), the weighted mean, in Table 3, of the left-oriented letters yields $41 \%$ reversal, and that of the right-oriented letters yields $21 \%$ reversal. If we look at the letters in a restricted sample of letters, without the mirror-letters and the insufficiently tested letters $j, q, r, t, y$, the weighted mean percentage reversal of the left-oriented letters yields, $43 \%$ reversal, whereas that of the rightoriented letters yields $22 \%$.

To answer the question whether visual mirror discrimination is associated with (for the symbolic icons) or explains (for the letters) reversal in writing, we analyzed the relation between the two tasks as follows.

First, we performed a linear regression of the percentage of reversed writings (restricted to the 12 letters tested in all replicates) in the baseline writing task on the number of correctly discriminated mirrored letters. For the 93 participants with data available in both tasks, the explained variance was less than $1 \%\left(R_{\mathrm{adj}}^{2}=0.009\right)$, and the effect of discrimination non-significant, $F(1,91)=$ $1.86, p=0.18$. In contrast, the analogous regression on the number of correctly discriminated mirrored symbols (icons) explained $13 \%$ of the variance, $R_{\mathrm{adj}}^{2}=0.13$, and was highly significant, $F(1,91)=14.34, p<0.001$.

Second, with the reversal data in the immediate and longterm tests for the $\mathrm{C}$ and $\mathrm{AC}$ groups (as in Table 3), we performed similar linear regressions in the group of 40 participants with data available in both tasks. The results confirm the precedents. Mirrored letters discrimination does not explain the percentage of reversal in writing, $R_{\mathrm{adj}}^{2}<0$, $F(1,38)=0.23, p=0.63$, whereas mirrored symbols (icons) discrimination does explain it substantially, $R_{\mathrm{adj}}^{2}=0.33$, and significantly, $F(1,38)=19.83, p<0.001$.

\subsection{Discussion}

Preliminary, we would note that mirror invariance only predicts left-right reversal (horizontal mirror). Tables 2, 3 show that horizontal mirroring was indeed, and often considerably, more frequent than vertical or double mirroring. This verification may be complicated by the vertical or double mirror writings that coincide with their correct writing (this is the case for the letters $\mathrm{c}$, s, and z: see Figure 2). But it is unrealistic to consider a correct writing as resulting from an inversion or double reversal of the displayed letter. It therefore seems relevant to focus only on horizontal mirror writing (i.e., reversing).

With respect to the models hypotheses for the crucial letters $b$ and $d$, the results do not confirm the prediction of Model 1, because there are far more than $50 \%$ reversals of $b$ and $\mathrm{d}$, separately, in Tables 2,3 . In addition, there are far more than $25 \%$ reversals of both b and d, simultaneously. The prediction of Model 3 is also not confirmed as both Tables 2, 3 show a very high percentage of $b$ reversals when none were predicted; the prediction of many reversals of $d$, however, is correct. In fact, only Model 2 remains viable to explain the reversal of both $b$ and $d$. Indeed, in this model, mirrorimaging arises spontaneously and intrudingly, possibly because the balance between the representations of $b$ and $d$ has been disturbed. Nevertheless, Corballis (2018), using the adverb "sometimes" for such intrusions, doesn't really suggest the observed, almost systematically, reversal of b and d (it is true that he did not consider the very particular conditions of writing used in the research of Torres et al., 2021).

The clear difference between reversal of the left-oriented and right-oriented letters among the non-reversible letters are rather consistent with Fischer and coworker's right orientation rule. The letters mainly contradicting this rule are "a" and "g," which were categorized left-oriented and therefore should be often reversed, and "s," which is categorized right-oriented and therefore should be rarely reversed. These letters suggest that, in fact, it is probably the dynamics of the writing that matters, not the intuitive aspect expressed in the verb "face" or "look towards" (the left for "a" and "g," or right for "s"). For example, given the two components of the handwritten letter "g," we usually starts with the loop and, then, trace the second component (a vertical line, curved at its end) on its right. Thus, the dynamics of writing runs left (the loop) to right (the line). This importance of the dynamics of writing was already noted by Fischer (2013) for the digit 4, which does not clearly face or look towards the right but was nevertheless categorized rightoriented.

The role of the direction of writing must also be taken into account to explain complete mirror writing (i.e., right-to-left writing, each letter being reversed) of the first name (Fischer and Tazouti, 2012; Fischer and Koch, 2016) or other words (Portex et al., 2018), as the sole confusion of mirrored letters cannot explain such complete mirror writing. Figure 3 illustrates Eddy's name writing at two different times, one under spatial constraints favoring mirror writing (left side of Figure 3) and the other in usual writing condition (right side of Figure 3). This children's behavioral adaptation to the 

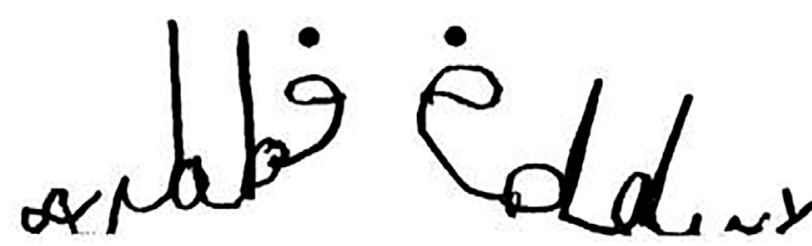

FIGURE 3 | Eddy's writing of his name, at age 6 years and 3 months, with his usual right hand in two different conditions (data from Fischer and Tazouti, 2012); note the reversal of $d$ in $b$ in the left part of the figure.

direction of writing in their culture suggests that the reversal of characters is also driven by underlying latent processes other than inhibition (Huster et al., 2020).

Finally, if reliable ${ }^{3}$, the results on the relation between reversal in the writing task and mirrored images discrimination in the visual task are of great importance. This because they strongly support both the hypothesis that good visual discrimination of mirrored letters does not significantly reduce mirror reversal in writing and that the effect of visual discrimination of other mirrored symbols (icons) cannot be interpreted causally. The latter interpretation should be "predictive," not "counterfactual," with the distinction of the interpretation of regression coefficients introduced by Gelman et al. (2021). In a pedagogical perspective, a counterfactual effect would have made it possible to teach image discrimination and, as a result, to expect a reduction of reversal in writing. This is clearly not the case.

\section{AN ACCOMMODATED MODEL?}

Because none of the three models predicts, or "retrodicts" (McElreath, 2020), the writing data of Torres et al., we sought to develop a model by combining some of their combinable strengths into a model thus qualified as accommodated. The first and third model do not take into account a possible difference between the cerebral hemispheres. Therefore, it is possible to simply accommodate these models in making playing a differential role to the two hemispheres.

In the discussion of Corballis (2018), Fischer and Luxembourger (2018b) do not exclude that the un-oriented representation of the characters in children's memory can be supported by a differential representation of the characters in the two hemispheres. This is not exactly Corballis (2018) theory, which predicts the two representations in both hemispheres. But, since learning of a verbal material is mainly processed in the left hemisphere, we hypothesize that the strength of the mirror-image representation obtained through interhemispheric transfer is stronger in the right hemisphere than the veridic representation (cf.,

${ }^{3}$ Our reservation comes not only from our surprising observation in the writing task, but also from some flaws in the visual task (in particular, the image-icons, half of which show axial symmetry).
Corballis and Beale, 1993; Corballis et al., 2010) ${ }^{4}$. Thus, we suggest that when children are presented with reversible letters, or some other letters whose orientation is difficult to memorize (mainly the letters $z$ and $s$, which seem to be reversible if you round the angles of the $\mathrm{z}$ and which, in any case, have a symmetry center), they resort to the wrong hemisphere (generally the right). This suggestion seems plausible because, with a model of complementary of the two hemispheres (Badzakova-Trajkov et al., 2016), the visual word form area (VWFA, in the left hemisphere) can recruit resources in the right hemisphere for processing mirror-reversed words when the task demands it (Ryan and Schnyer, 2007). People who are aware of a visual cue activate more the right temporo-parietal junction than people who are not (Wilterson et al., 2021). In pigeons, commissural exchange can compensate hemispheric differences in visual object discrimination and commissural interactions flexibly adjust neural processes of the left and right hemisphere (Xiao and Güntürkün, 2021). In general, visual working memory undergoes developmental changes, becoming relatively more left-lateralized in adult humans (Matejko and Ansari, 2021). Specifically, learning to mirror-read progressed from reliance upon right hemisphere dorsal stream visuo-spatial processes to a reliance upon left-hemisphere ventral stream object recognition processes in the research by Poldrack et al. (1998), and switching from plain text to mirror-reading engaged the right parietal cortex in the research by Jimura et al. (2014). The fact that the children reverse, almost systematically, the letters $\mathrm{b}$ and $\mathrm{d}$, and, though less systematically, the letters $\mathrm{p}, \mathrm{q}, \mathrm{z}$ and $\mathrm{s}$, suggest that in this (right) hemisphere the neuronal circuits of $b$ and $d$ representation, and of the other letters are laid down in mirror fashion. In addition, because the letter $b$ was presented first in the Torres et al. (2021) writing test, the wrong hemisphere was initially activated and thus could intervene promptly on a later occasion. For the letters without specific orientation problem (e.g., c-e-r), the children use the other hemisphere (generally the left) and have a less strong representation of their mirror image.

Importantly, this accommodated model does not contradict many specific observations of dyslexic children. For example, that they fail to automatize mirror discrimination during visual object processing (Fernandes and Leite, 2017), or that "children with dyslexia fail to suppress symmetry generalization" (Lachmann and van Leeuwen, 2007 p. 73). Moreover, the accommodated model fits well with Mather (2001) viewing of developmental dyslexia as the outcome of learning to write the alphabet in the non-dominant (right) hemisphere.

However, a major question yet is not answered by this accommodated model: What was the role of blindfolded writing?

${ }^{4}$ Without such an adaptation, Corballis (2018) theory should be paradoxical. He claims that a perfectly symmetrical organism would be incapable of saying "bee " to a $b$ and « dee " to a $d$. Thus, even if an image and its mirror are represented both in the left and the right hemisphere, these representations must differ between the hemispheres. 
It is obvious that writing with eyes closed is largely responsible for the curious observation that children invert both $\mathrm{b}$ in $\mathrm{d}$ and $\mathrm{d}$ in $\mathrm{b}$. The finding by Weng et al. (2020) that brain activity may be more unstable with eyes closed than with eyes open is not explanatory, because instability is contradicted by the almost systematic reversal of $\mathrm{b}$ and $\mathrm{d}$ that we observed. Since the PET study by Kosslyn et al. (1995), we know that the primary visual cortex is activated when subjects close their eyes and visualize objects. Interestingly, Costumero et al. (2020) showed that the functional connectivity of $\mathrm{V} 1$ is modulated by the resting-state ${ }^{5}$ eye condition and that V1 was positively coupled with the default mode network and sensorimotor network during closed eyes. This advantage of the closed eyes condition results partially from reducing interference from other visual inputs, thereby allowing better concentration on mental images. Indeed, eyes open and closed conditions by themselves are associated with significant changes in functional connectivity. Volitional opening the eyes perturbs the brain dynamics and functional connectivity (Jao et al., 2013; Xu et al., 2014). Closing eyes enhances brain intrinsic activity in the visual networks (Zhang et al., 2019), and increases connectivity in sensorimotor and auditory networks by allowing the brain to focus more on other senses (Agcaoglu et al., 2019). More generally, Xu et al. (2014) describe the eyes as acting as a toggle between exteroceptive and interoceptive networks.

These findings, obtained through fMRI on adult participants in resting-state, often suggest an advantage for brain intrinsic activity in the closed eyes condition. However, contrary to adults, the intrinsic functional networks does not predict cognition in children-preschoolers, early and late school-age children (Zhang et al., 2020). This leads us to verify whether eyes closing advantaged children in behavioral observations. We found only three studies in our search. All tested similarly memory recall in children. Natali et al. (2012) found that eye closure improves 11 years-old children's recall, and Mastroberardino et al. (2012) found the same but only for cued recall in 6 years-old children. The two experiments by Kyriakidou et al. (2014), on 6-12 and 9-13 years-old children, respectively, found inconsistent results. However, the experiment including 6 years-old children confirmed the advantage of the eyes closed condition and the second experiment found no difference between closed and open-eyes conditions. Thus, the eyes closed condition also seems somewhat advantageous in 6 years-old children. Why should then Torres et al.'s blindfolded writing task have a disadvantageous effect, causing systematic reversal of $b$ and $d$ ?

Even in usual condition, the visual system must infer which external cause is most likely, given both the sensory data and prior knowledge. Born and Bencomo (2020) argue that this approach to "seeing" makes our visual systems prone to perceptual errors. In the eyes masked condition, the role of top-down feedback in the

${ }^{5}$ If one wonders that we refer to resting-state, we would justify this reference with two complementary reasons: 1) With the discovery of the brain's default mode network, research concentrated on resting-state; 2) The brain's default mode network is important because brain's functions are mainly intrinsic and ongoing (Raichle, 2015). visual system will be exacerbated. For example, Götz et al. (2017) attributed eye closure disadvantage for spatial discrimination to the requirement of at least one top-down processing stage. A complex activity, such as Torres et al. (2021) letter writing task proposed to children who have already partly memorized the letters, implies certainly top-down processing. In continuity with our accommodated model previously outlined, we speculate that this top-down processing favored the intrusion of the reversed letters ( $\mathrm{d}$ and $\mathrm{b}$ ) from the highly activated right hemisphere in children's working visual memory. This top-down influence is consistent with, or at least does not contradict the lower brain activity in sensorimotor system areas in an eyes closed restingstate (Wei et al., 2018) and the increasing homotopic resting-state functional connectivity in sensorimotor regions with age, beginning at age 7 (Zuo et al., 2010).

\section{CONCLUSION}

The observation in Torres et al. (2021) data-when presented with $b$ the great majority of the children write $d$, and when presented with $\mathrm{d}$ the same children write $\mathrm{b}$-was really surprising: Why do the Brazilian first-graders systematically respond the reversed image (for b and d), rather than the image they have seen, thus following the pigeons (Mello, 1965), the monkeys with sectioned chiasmas (Noble, 1966), and the right hemisphere of the callotomized patient DDV (of Corballis et al., 2010)?

Our curious observation certainly results from the particular task the authors used, mainly from its complexity: copying a letter after a time-limited displaying of the letter ( $3 \mathrm{~s}$ ) and, above all, writing without visual control, with eyes masked. This curiosity is exacerbated by the fact that visual discrimination of mirrored letters does not explain-not even correlate with-mirror writing, whereas visual discrimination of other mirrored images (icons) correlates statistically with mirror writing.

None of the three models examined can convincing explain the observation. An accommodated model integrating the fundamental component of Corballis (2018) model, that is, reversal during interhemispheric transfer in memory, accounts for the observed data. This model suggests that, in case of difficulty, children recruit the second (usually right) hemisphere, which-this is a strong assumption of the model-contains a representation of the mirror image, notably of that of the mirror-letters. For letters whose orientation is consistent with the direction of writing and which present no other difficulty, such recruitment is unnecessary and avoids children having to resort to the mirror-image of the letter they have seen, a recourse that leads them to reverse $b$ and $d$ in particular.

However, this accommodated model suffers from the double fact that it is based on a surprising result, which we observed in Torres et al. (2021) data but which has never been replicated (to this day), and that it is the result of an a posteriori construct generally considered to be of low scientific value. A call for replication is therefore required, but may not be heard because 
the entire research of Torres et al. (2021) is very complex. Moreover, a restricted research on mirror writing and visual discrimination of symmetrical images alone is terribly frustrating because it would deprive researchers of a possible confirmation of the major and important pedagogical finding of Torres et al., that is, "a simple, low-tech, and accessible method that can efficiently unleash the reading fluency potential of first graders" and thus "can benefit millions of children worldwide" (pp. 8-9).

\section{DATA AVAILABILITY STATEMENT}

Publicly available datasets were analyzed in this study. This data can be found here: https://osf.io/643jh/https://osf.io/qc8bn.

\section{REFERENCES}

Agcaoglu, O., Wilson, T. W., Wang, Y. P., Stephen, J., and Calhoun, V. D. (2019). Resting State Connectivity Differences in Eyes Open versus Eyes Closed Conditions. Hum. Brain Mapp. 40 (8), 2488-2498. doi:10.1002/hbm.24539

Ahmed, Y., Wagner, R. K., and Lopez, D. (2014). Developmental Relations between reading and Writing at the Word, Sentence, and Text Levels: A Latent Change Score Analysis. J. Educ. Psychol. 106 (2), 419-434. doi:10.1037/a0035692

Ahr, E., Houdé, O., and Borst, G. (2016). Inhibition of the Mirror Generalization Process in reading in School-Aged Children. J. Exp. Child Psychol. 145, 157-165. doi:10.1016/j.jecp.2015.12.009

Ahr, E., Houdé, O., and Borst, G. (2017). Predominance of Lateral over Vertical Mirror Errors in reading: A Case for Neuronal Recycling and Inhibition. Brain Cogn. 116, 1-8. doi:10.1016/j.bandc.2017.03.005

Antinucci, P., and Hindges, R. (2018). Orientation-selective Retinal Circuits in Vertebrates. Front. Neural Circuits 12, 11. doi:10.3389/fncir.2018.00011

Badzakova-Trajkov, G., Corballis, M. C., and Häberling, I. S. (2016). Complementarity or independence of Hemispheric Specializations? A Brief Review. Neuropsychologia 93, 386-393. doi:10.1016/ j.neuropsychologia.2015.12.018

Blackburne, L. K., Eddy, M. D., Kalra, P., Yee, D., Sinha, P., and Gabrieli, J. D. E. (2014). Neural Correlates of Letter Reversal in Children and Adults. PLoS ONE 9 (5), e98386. doi:10.1371/journal.pone.0098386

Born, R. T., and Bencomo, G. M. (2020). Illusions, Delusions, and Your Backwards Bayesian Brain: a Biased Visual Perspective. Brain Behav. Evol. 95, 272-285. doi:10.1159/000514859

Bornstein, M. H., Gross, C. G., and Wolf, J. Z. (1978). Perceptual Similarity of Mirror Images in Infancy. Cognition 6 (2), 89-116. doi:10.1016/0010-0277(78) 90017-3

Borst, G., Ahr, E., Roell, M., and Houdé, O. (2015). The Cost of Blocking the Mirror Generalization Process in reading: Evidence for the Role of Inhibitory Control in Discriminating Letters with Lateral Mirror-Image Counterparts. Psychon. Bull. Rev. 22 (1), 228-234. doi:10.3758/s13423-014-0663-9

Brault Foisy, L.-M., Ahr, E., Masson, S., Houdé, O., and Borst, G. (2017). Is Inhibitory Control Involved in Discriminating Pseudowords that Contain the Reversible Letters B and D? J. Exp. Child Psychol. 162, 259-267. doi:10.1016/ j.jecp.2017.05.011

Bryant, P. E. (1973). Discrimination of Mirror Images by Young Children. J. Comp. Physiol. Psychol. 82, 415-425. doi:10.1037/h0034141

Bryant, P. E. (1969). Perception and Memory of the Orientation of Visually Presented Lines by Children. Nature 224, 1331-1332. doi:10.1038/2241331a0 Brysbaert, M., and Stevens, M. (2018). Power Analysis and Effect Size in Mixed Effects Models: a Tutorial. J. Cogn. 1 (1), 9. doi:10.5334/joc.10

Cheng-Lai, A., Li-Tsang, C. W. P., Chan, A. H. L., and Lo, A. G. W. (2013). Writing to Dictation and Handwriting Performance Among Chinese Children with Dyslexia: Relationships with Orthographic Knowledge and Perceptual-Motor Skills. Res. Develop. Disabilities 34 (10), 3372-3383. doi:10.1016/ j.ridd.2013.06.039

\section{ETHICS STATEMENT}

Ethical review and approval was not required for the study on human participants in accordance with the local legislation and institutional requirements. Written informed consent for participation was not required for this study in accordance with the national legislation and the institutional requirements.

\section{AUTHOR CONTRIBUTIONS}

JPF analyzed the data, and wrote the first draft of the article. Both authors conceptualized the study, edited the article, and approved the final draft.

Clark, H. H. (1973). The Language-As-Fixed-Effect Fallacy: A Critique of Language Statistics in Psychological Research. J. Verbal Learn. Verbal Behav. 12 (4), 335-359. doi:10.1016/S0022-5371(73)80014-3

Corballis, M. C., and Beale, I. L. (1993). “Orton Revisited: Dyslexia, Laterality, and Left-Right Confusion," in Visual Processes in reading and reading Disabilities. Editors D. M. Willows, R. S. Kruk, and E. M. Corcos (Hillsdale (NJ): Erlbaum), $57-74$.

Corballis, M. C., and Beale, I. L. (1976). The Psychology of Left and Right. New York: Erlbaum.

Corballis, M. C., Birse, K., Paggi, A., Manzoni, T., Pierpaoli, C., and Fabri, M. (2010). Mirror-image Discrimination and Reversal in the Disconnected Hemispheres. Neuropsychologia 48, 1664-1669. doi:10.1016/ j.neuropsychologia.2010.02.011

Corballis, M. C. (2018). Mirror-image Equivalence and Interhemispheric Mirror-Image Reversal. Front. Hum. Neurosci. 12, 140. doi:10.3389/ fnhum.2018.00140

Corballis, M. C., and Zalik, M. C. (1977). Why Do Children Confuse Mirror-Image Obliques? J. Exp. Child Psychol. 24 (3), 516-523. doi:10.1016/0022-0965(77) 90095-9

Costumero, V., Bueichekú, E., Adrián-Ventura, J., and Ávila, C. (2020). “Opening or Closing Eyes at Rest Modulates the Functional Connectivity of V1 with Default and Salience Networks," in Natureresearch: Scientific Reports. Available at: https://www.nature.com/articles/s41598-020-66100-y.pdf. doi:10.1038/ s41598-020-66100-y

Dehaene, S. (2009). Reading in the Brain: The New Science of How We Read. (London: Penguin Books).

Dilks, D. D., Julian, J. B., Kubilius, J., Spelke, E. S., and Kanwisher, N. (2011). Mirror-image Sensitivity and Invariance in Object and Scene Processing Pathways. J. Neurosci. 31 (31), 11305-11312. doi:10.1523/JNEUROSCI.193511.2011

Dragoi, V., Sharma, J., and Sur, M. (2000). Adaptation-induced Plasticity of Orientation Tuning in Adult Visual Cortex. Neuron 28, 287-298. doi:10.1016/S0896-6273(00)00103-3

Duñabeitia, J. A., Molinaro, N., and Carreiras, M. (2011). Through the LookingGlass: Mirror reading. NeuroImage 54 (4), 3004-3009. doi:10.1016/ j.neuroimage.2010.10.079

Eichenbaum, H. (2004). Hippocampus. Neuron 44 (1), 109-120. doi:10.1016/ j.neuron.2004.08.028

Fernandes, T., and Leite, I. (2017). Mirrors Are Hard to Break: A Critical Review and Behavioral Evidence on Mirror-Image Processing in Developmental Dyslexia. J. Exp. Child Psychol. 159, 66-82. doi:10.1016/j.jecp.2017.02.003

Fischer, J.-P. (2017). Character Reversal in Children: The Prominent Role of Writing Direction. Read. Writ 30 (3), 523-542. doi:10.1007/s11145-016-9688-y

Fischer, J.-P. (2013). Digit Reversal in Children's Writing: A Simple Theory and its Empirical Validation. J. Exp. Child Psychol. 115, 356-370. doi:10.1016/ j.jecp.2013.02.003

Fischer, J.-P., and Koch, A.-M. (2016). Mirror Writing in Typically Developing Children: a First Longitudinal Study. Cogn. Develop. 38, 114-124. doi:10.1016/ j.cogdev.2016.02.005 
Fischer, J.-P., and Luxembourger, C. (2018a). A Synoptic and Theoretical Account of Character (Digits and Capital Letters) Reversal in Writings by Typically Developing Children. Educ. Sci. 8 (3), 137. doi:10.3390/educsci8030137

Fischer, J.-P., and Luxembourger, C. (2018b). Commentary: Mirror-Image Equivalence and Interhemispheric Mirror-Image Reversal. Front. Hum. Neurosci. 12, e375. doi:10.3389/fnhum.2018.00375

Fischer, J.-P., and Luxembourger, C. (2020). The Battle between the Correct and Mirror Writings of a Digit in Children's Recognition Memory. Educ. Sci. 10 (7), 183. doi:10.3390/educsci10070183

Fischer, J.-P. (2018). Studies on the Written Characters Orientation and its Influence on Digit Reversal by Children. Educ. Psychol. 38 (5), 556-571. doi:10.1080/01443410.2017.1359239

Fischer, J.-P., and Tazouti, Y. (2012). Unraveling the Mystery of Mirror Writing in Typically Developing Children. J. Educ. Psychol. 104 (1), 193-205. doi:10.1037/ a0025735

Fischer, J.-P., and Thierry, X. (2021). Miswriting (Especially Mirror Writing) of the Digits: An Ecological Assessment Using ELFE Data. J. Cogn. Educ. Psych 20 (1), 3-17. doi:10.1891/JCEP-D-19-00053

Fischer, J. P. (1999). Le rôle exclusivement positif des erreurs: une conception erronée de l'apprentissage. Résonances 5, 9-11.

Freiwald, W. A., and Tsao, D. Y. (2010). Functional Compartmentalization and Viewpoint Generalization within the Macaque Face-Processing System. Science 330, 845-851. doi:10.1126/science.1194908

Garg, A. K., Li, P., Rashid, M. S., and Callaway, E. M. (2019). Color and Orientation Are Jointly Coded and Spatially Organized in Primate Primary Visual Cortex. Science 364 (6447), 1275-1279. doi:10.1126/science.aaw5868

Gelman, A., Hill, J., and Vehtari, A. (2021). Regression and Other Stories. (Cambridge: University Press).

Gordon, H. W. (1980). Cognitive Asymmetry in Dyslexic Families. Neuropsychologia 18 (6), 645-656. doi:10.1016/0028-3932(80)90104-9

Götz, T., Hanke, D., Huonker, R., Weiss, T., Klingner, C., Brodoehl, S., et al. (2017). The Influence of Eye Closure on Somatosensory Discrimination: a Trade-Off between Simple Perception and Discrimination. Cereb. Cortex 27, 3231-3239. doi:10.1093/cercor/bhx089

Hubel, D. H., Wiesel, T. N., and Stryker, M. P. (1977). Orientation Columns in Macaque Monkey Visual Cortex Demonstrated by the 2-deoxyglucose Autoradiographic Technique. Nature 269, 328-330. doi:10.1038/269328a0

Huster, R. J., Messel, M. S., Thunberg, C., and Raud, L. (2020). The P300 as Marker of Inhibitory Control - Fact or Fiction? Cortex 132, 334-348. doi:10.1016/ j.cortex.2020.05.021

Jao, T., Vértes, P. E., Alexander-Bloch, A. F., Tang, I.-N., Yu, Y.-C., Chen, J.-H., et al. (2013). Volitional Eyes Opening Perturbs Brain Dynamics and Functional Connectivity Regardless of Light Input. NeuroImage 69, 21-34. doi:10.1016/ j.neuroimage.2012.12.007

Jia, K., Li, Y., Gong, M., Huang, H., Wang, Y., and Li, S. (2021). Perceptual Learning beyond Perception: Mnemonic Representation in Early Visual Cortex and Intraparietal Sulcus. J. Neurosci. 41, 4476-4486. doi:10.1523/ JNEUROSCI.2780-20.2021

Jimura, K., Cazalis, F., Stover, E. R. S., and Poldrack, R. A. (2014). The Neural Basis of Task Switching Changes with Skill Acquisition. Front. Hum. Neurosci. 8, 339. doi:10.3389/fnhum.2014.00339

Judd, C. M., Westfall, J., and Kenny, D. A. (2017). Experiments with More Than One Random Factor: Designs, Analytic Models, and Statistical Power. Annu. Rev. Psychol. 68 (1), 601-625. doi:10.1146/annurev-psych-122414-033702

Kim, Y.-S. G., Petscher, Y., Wanzek, J., and Al Otaiba, S. (2018). Relations between reading and Writing: a Longitudinal Examination from Grades 3 to 6. Read. Writ 31 (7), 1591-1618. doi:10.1007/s11145-018-9855-4

Kolinsky, R., Verhaeghe, A., Fernandes, T., Mengarda, E. J., Grimm-Cabral, L., and Morais, J. (2011). Enantiomorphy through the Looking Glass: Literacy Effects on Mirror-Image Discrimination. J. Exp. Psychol. Gen. 140 (2), 210-238. doi:10.1037/a0022168

Kosslyn, S. M., Thompson, W. L., Klm, I. J., and Alpert, N. M. (1995). Topographical Representations of Mental Images in Primary Visual Cortex. Nature 378, 496-498. doi:10.1038/378496a0

Kyriakidou, M., Blades, M., and Carroll, D. (2014). Inconsistent Findings for the Eyes Closed Effect in Children: the Implications for Interviewing Child Witnesses. Front. Psychol. 5, 448. doi:10.3389/fpsyg.2014.00448
Lachmann, T. (2008). "Experimental Approaches to Specific Disabilities in Learning to Read: The Case of Symmetry Generalization in Developmental Dyslexia," in Advances in Cognitive Science. Editors N. Srinivasan, A. K. Gupta, and J. Pandey (Thousand Oaks, CA: Sage), 321-342.

Lachmann, T., and Geyer, T. (2003). Letter Reversals in Dyslexia: Is the Case Really Closed? A Critical Review and Conclusions. Psychol. Sci. 45, 53-75.

Lachmann, T., and van Leeuwen, C. (2007). Paradoxical Enhancement of Letter Recognition in Developmental Dyslexia. Develop. Neuropsychol. 31, 61-77. doi:10.1080/8756564070933688710.1207/s15326942dn3101_4

Longcamp, M., Velay, J.-1., Berninger, V. W., and Richards, T. (2016). Neuroanatomy of Handwriting and Related reading and Writing Skills in Adults and Children with and without Learning Disabilities: French-American Connections. Pratiques 171-172, 1-11. doi:10.4000/pratiques.3175

Madan, C. R., and Singhal, A. (2021). Convergent and Distinct Effects of Multisensory Combination on Statistical Learning Using a Computer Glove. Front. Psychol. 11, 599125. doi:10.3389/fpsyg.2020.599125

Mastroberardino, S., Natali, V., and Candel, I. (2012). The Effect of Eye Closure on Children's Eyewitness Testimonies. Psychol. Crime L. 18 (3), 245-257. doi:10.1080/10683161003801100

Matejko, A. A., and Ansari, D. (2021). Shared Neural Circuits for Visuospatial Working Memory and Arithmetic in Children and Adults. J. Cogn. Neurosci. 33 (6), 1003-1019. doi:10.1162/jocn_a_01695

Mather, D. S. (2001). Does Dyslexia Develop from Learning the Alphabet in the Wrong Hemisphere? A Cognitive Neuroscience Analysis. Brain Lang. 76 (3), 282-316. doi:10.1006/brln.2000.2424

Mather, D. S., Milford, T. M., and Mcrae, L. M. (2015). Does Dyslexia Develop from Left-Eye Dominance? Percept Mot. Skills 121 (2), 569-601. doi:10.2466/ 15.10.PMS.121c21x5

McElreath, R. (2020). Statistical Rethinking: A Bayesian Course with Examples in $R$ and Stan. Second Edition. (Boca Raton (FL): CRC Press).

McIntosh, R. D., Anderson, E. L., and Henderson, R. M. (2018a). Experimental Confirmation of a Character-Facing Bias in Literacy Development. J. Exp. Child Psychol. 170, 207-214. doi:10.1016/j.jecp.2018.01.011

McIntosh, R. D., Hillary, K., Brennan, A., and Lechowicz, M. (2018b). Developmental Mirror-Writing Is Paralleled by Orientation Recognition Errors. Laterality: Asymmetries Body, Brain Cogn. 23 (6), 664-683. doi:10.1080/1357650X.2018.1445748

McNaughton, N., and Wickens, J. (2003). Hebb, Pandemonium and Catastrophic Hypermnesia: the hippocampus as a Suppressor of Inappropriate Associations. Cortex 39, 1139-1163. doi:10.1016/S0010-9452(08)70882-7

Mello, N. K. (1965). Interhemispheric Reversal of Mirror-Image Oblique Lines after Monocular Training in Pigeons. Science 148, 252-254. doi:10.1126/ science.148.3667.252

Menon, V., and Chang, H. (2021). Emerging Neurodevelopmental Perspectives on Mathematical Learning. Develop. Rev. 60, 100964. doi:10.1016/j.dr.2021.100964

Natali, V., Marucci, F. S., and Mastroberardino, S. (2012). Long-Term Memory Effects of Eye Closure on Children Eyewitness Testimonies. Appl. Cognit. Psychol. 26 (5), 730-736. doi:10.1002/acp.2853

Noble, J. (1966). Mirror-images and the Forebrain Commissures of the Monkey. Nature 211, 1263-1266. doi:10.1038/2111263a0

Orton, S. T. (1925). "Word-blindness" in School Children. Arch. Neurpsych 14 (5), 581-615. doi:10.1001/archneurpsyc.1925.02200170002001

Orton, S. T., and Gillingham, A. (1933). "Special Disability in Writing," in Bulletin of the Neurological Institute of New York, 3(1↔2). Reproduced in S. T. Orton. Reading, writing, and speech problems in children and selected papers. (Baltimore: The International Dyslexia Association). 267-292.

Ouzoulias, A., Fischer, J.-P., and Brissiaud, R. (2000). Comparaison de deux scénarios d'appropriation du lexique écrit. enfan 53, 393-416. doi:10.3406/ enfan.2000.3193

Over, R. (1967). Detection and Recognition Measures of Shape Discrimination. Nature 214, 1272-1273. doi:10.1038/2141272a0

Over, R., and Over, J. (1967). Detection and Recognition of Mirror-Image Obliques by Young Children. J. Comp. Physiol. Psychol. 64 (3), 467-470. doi:10.1037/ h0025182

Pegado, F., Nakamura, K., and Hannagan, T. (2014). How Does Literacy Break Mirror Invariance in the Visual System? Front. Psychol. 5, 703. doi:10.3389/ fpsyg. 2014.00703 
Perea, M., Moret-Tatay, C., and Panadero, V. (2011). Suppression of Mirror Generalization for Reversible Letters: Evidence from Masked Priming. J. Mem. Lang. 65 (3), 237-246. doi:10.1016/j.jml.2011.04.005

Poldrack, R., Desmond, J. E., Glover, G. H., and Gabrieli, J. D. E. (1998). The Neural Basis of Visual Skill Learning: an fMRI Study of Mirror reading. Cereb. Cortex 8 (1), 1-10. doi:10.1093/cercor/8.1.1

Portex, M., Hélin, C., Ponce, C., and Foulin, J.-N. (2018). Dynamics of Mirror Writing Compared to Conventional Writing in Typical Preliterate Children. Read. Writ 31 (6), 1435-1448. doi:10.1007/s11145-018-9838-5

Priebe, N. J. (2016). Mechanisms of Orientation Selectivity in the Primary Visual Cortex. Annu. Rev. Vis. Sci. 2, 85-107. doi:10.1146/annurev-vision-111815114456

Raichle, M. E. (2015). The Restless Brain: How Intrinsic Activity Organizes Brain Function. Phil. Trans. R. Soc. B 370, 20140172. doi:10.1098/rstb.2014.0172

Richmond, J. (2012). "Letter and Number Reversals - Identifying the Problem," in Poster presented at the Occupational Therapy Association of Australian Northern Territory Conference, Darwin, Northern Territory, Australia, June 8, 2012.

Rollenhagen, J. E., and Olson, C. R. (2000). Mirror-image Confusion in Single Neurons of the Macaque Inferotemporal Cortex. Science 287, 1506-1508. doi:10.1126/science.287.5457.1506

Ryan, L., and Schnyer, D. (2007). Regional Specificity of Format-specific Priming Effects in Mirror Word reading Using Functional Magnetic Resonance Imaging. Cereb. Cortex 17 (4), 982-992. doi:10.1093/cercor/bhl009

Simner, M. L. (2003). Promoting Skilled Handwriting. Ottawa: Canadian Psychological Association.

Simner, M. L. (1984). The Grammar of Action and Reversal Errors in Children's Printing. Develop. Psychol. 20 (1), 136-142. doi:10.1037/0012-1649.20.1.136

Soares, A. P., Lages, A., Oliveira, H., and Hernández, J. (2019). The Mirror Reflects More for D Than for B: Right Asymmetry Bias on the Visual Recognition of Words Containing Reversal Letters. J. Exp. Child Psychol. 182, 18-37. doi:10.1016/j.jecp.2019.01.008

Soares, A. P., Lages, A., Velho, M., Oliveira, H. M., and Hernández-Cabrera, J. (2021). The Mirror Reflects More for Genial Than for Casual: RightAsymmetry Bias on the Visual Word Recognition of Words Containing Non-reversal Letters. Read. Writ 34, 1467-1489. doi:10.1007/s11145-02010100-x

Squire, L. R. (1992). Memory and the hippocampus: A Synthesis from Findings with Rats, Monkeys, and Humans. Psychol. Rev. 99 (2), 195-231. doi:10.1037/ 0033-295X.99.2.195

Torres, A. R., Mota, N. B., Adamy, N., Naschold, A., Lima, T. Z., Copelli, M., et al. (2021). Selective Inhibition of Mirror Invariance for Letters Consolidated by Sleep Doubles reading Fluency. Curr. Biol. 31, 742-752. doi:10.1016/ j.cub.2020.11.031

Treiman, R., Gordon, J., Boada, R., Peterson, R. L., and Pennington, B. F. (2014). Statistical Learning, Letter Reversals, and reading. Scientific Stud. Reading 18 (6), 383-394. doi:10.1080/10888438.2013.873937

Treiman, R., and Kessler, B. (2014). How Children Learn to Write Words.(Oxford: Scholarship Online: Oxford University Press). doi:10.1093/acprof:oso/ 9780199907977.001.0001

Treiman, R., and Kessler, B. (2011). Similarities Among the Shapes of Writing and Their Effects on Learning. WL\&L 14 (1), 39-57. doi:10.1075/wll.14.1.03tre

Treiman, R. (2017). Learning to Spell Words: Findings, Theories, and Issues. Scientific Stud. Reading 21 (4), 265-276. doi:10.1080/10888438.2017.1296449
Viganò, S., Borghesani, V., and Piazza, M. (2021). Symbolic Categorization of Novel Multisensory Stimuli in the Human Brain. NeuroImage 235, 118016. doi:10.1016/j.neuroimage.2021.118016

Vlach, H. A., and Kalish, C. W. (2014). Temporal Dynamics of Categorization: Forgetting as the Basis of Abstraction and Generalization. Front. Psychol. 5, 1021. doi:10.3389/fpsyg.2014.01021

Wechsler, D., and Pignatelli, M. L. (1937). Reversal Errors in reading: Phenomena of Axial Rotation. J. Educ. Psychol. 28 (3), 215-221. doi:10.1037/h0062672

Wei, J., Chen, T., Li, C., Liu, G., Qiu, J., and Wei, D. (2018). Eyes-open and EyesClosed Resting States with Opposite Brain Activity in Sensorimotor and Occipital Regions: Multidimensional Evidences from Machine Learning Perspective. Front. Hum. Neurosci. 12, 422. doi:10.3389/fnhum.2018.00422

Weng, Y., Liu, X., Hu, H., Huang, H., Zheng, S., Chen, Q., et al. (2020). Open Eyes and Closed Eyes Elicit Different Temporal Properties of Brain Functional Networks. NeuroImage 222, 117230. doi:10.1016/j.neuroimage.2020.117230

Wilterson, A. I., Nastase, S. A., Bio, B. J., Guterstam, A., and Graziano, M. S. A. (2021). Attention, Awareness, and the Right Temporoparietal junction. Proc. Natl. Acad. Sci. USA 118 (25), e2026099118. doi:10.1073/pnas.2026099118

Xiao, Q., and Güntürkün, O. (2021). The Commissura Anterior Compensates Asymmetries of Visual Representation in Pigeons. Laterality 26 (1-2), 213-237. doi:10.1080/1357650X.2021.18895710.1080/1357650X.2021.1889577

Xu, P., Huang, R., Wang, J., Van Dam, N. T., Xie, T., Dong, Z., et al. (2014). Different Topological Organization of Human Brain Functional Networks with Eyes Open versus Eyes Closed. NeuroImage 90, 246-255. doi:10.1016/ j.neuroimage.2013.12.060

Zhang, D., Gao, Z., Liang, B., Li, J., Cai, Y., Wang, Z., et al. (2019). Eyes Closed Elevates Brain Intrinsic Activity of Sensory Dominance Networks: a Classifier Discrimination Analysis. Brain Connectivity 9 (2), 221-230. doi:10.1089/ brain.2018.0644

Zhang, H., Hao, S., Lee, A., Eickhoff, S. B., Pecheva, D., Cai, S., et al. (2020). Do intrinsic Brain Functional Networks Predict Working Memory from Childhood to Adulthood? Hum. Brain Mapp. 41 (16), 4574-4586. doi:10.1002/hbm.25143

Zuo, X.-N., Kelly, C., Di Martino, A., Mennes, M., Margulies, D. S., Bangaru, S., et al. (2010). Growing Together and Growing Apart: Regional and Sex Differences in the Lifespan Developmental Trajectories of Functional Homotopy. J. Neurosci. 30 (45), 15034-15043. doi:10.1523/JNEUROSCI.2612-10.2010

Conflict of Interest: The authors declare that the research was conducted in the absence of any commercial or financial relationships that could be construed as a potential conflict of interest.

Publisher's Note: All claims expressed in this article are solely those of the authors and do not necessarily represent those of their affiliated organizations, or those of the publisher, the editors and the reviewers. Any product that may be evaluated in this article, or claim that may be made by its manufacturer, is not guaranteed or endorsed by the publisher.

Copyright (c) 2021 Fischer and Luxembourger. This is an open-access article distributed under the terms of the Creative Commons Attribution License (CC $B Y$ ). The use, distribution or reproduction in other forums is permitted, provided the original author(s) and the copyright owner(s) are credited and that the original publication in this journal is cited, in accordance with accepted academic practice. No use, distribution or reproduction is permitted which does not comply with these terms. 